\title{
Physical Activity Combine Medical Nutrient Therapy to Control Glycemia Gestational Diabetes Mellitus in Hung Vuong Hospital, Vietnam
}

\author{
Huynh Nguyen Khanh Trang ${ }^{1,2}$, Pham Thi Bao Yen ${ }^{2}$, Tran Thi Ngoc Tam ${ }^{1}$ and Hoang Thi Diem Tuyet ${ }^{1 *}$ \\ ${ }^{1}$ Hung Vuong Hospital, Vietnam \\ ${ }^{2}$ University of Medicine Pham Ngoc Thach, Vietnam
}

Submission: May 01, 2019 ; Published: May 08, 2019

*Corresponding author: Hoang Thi Diem Tuyet, Hung Vuong Hospital, Vietnam

\begin{abstract}
Summary
Gestational diabetes mellitus (GDM) trend to rise in the world and in Vietnam. Diagnosis is not difficult and initial treatment with appropriate diet for good results. With proper physical activity and exercise coordination can help stabilize blood glucose better.

Objectives: To determine the rate of pregnant women with stable blood glucose levels when treated with a controlled combined diet and exercise regime at Hung Vuong Hospital.

Method: Quasi experimental study on 121 pregnant women with GDM treated with diet regimen at Department of High risk pregnany, Hung Vuong Hospital, HCMC from 12/2017 to 04/2018, eligible sample and agree to participate in research.

Results: [1] The prevalence of GDM with stable blood glucose after 3, 5 and 7 days of dietary restriction combined with physical activity by walking for 30 minutes per day were 71.2 95\%CI [63.2-79.1], 84.8 95\%CI [75.5-91.0] and 87.2 95\% CI [81.3-90.0] [2]. Combine with diet and exercise, level blood glucose stability with $\mathrm{RR}=2.67,95 \% \mathrm{CI}[1.03-6.92], \mathrm{P}<0.05$. Other unrecognized factors had statistically significant differences [3]. Total physical activity intensity of the study participants: 112.27 Met-hours/week [4,5].
\end{abstract}

Conclusion: Physical activity and exercise 30 minutes per day combined with dietary restriction helps stabilize blood sugar levels in pregnant women with GDM [6-9].

Keywords: Gestational Diabetes Mellitus; Dietary Restriction; Physical Activity and Exercise

Abbreviatations: IDF: International Diabetes Federation; GDM: Gestational Diabetes Mellitus; ADA: Ameriacan Diabetes Association; MNT: Medical Nutria Therapy

\section{Introduction}

In 2013, the International Diabetes Federation (IDF) estimated that about $16.6 \%$ live children from mothers with hyperglycemia during pregnancy. This report also noted a huge difference in the incidence of disease, up to $25 \%$ in Southeast Asia to $10.4 \%$ in North America and the Caribbean [10]. Of which, $91.6 \%$ gestational diabetes mellitus (GDM) comes from low-income and middle-income countries. In Vietnam, GDM is an issue of increasing concern, a series of epidemiological studies conducted in recent years, recognizing that the proportion of GDM is increasing in population. However, it is noteworthy that the frequency of diseases affected by the study population (performed at the hospital) or using the 1-step -75g diagnostic criteria (according to International Association of Diabetes and
Pregnancy Study Groups) can make much higher than the gener al screening or use of 2-100g standard (WHO) [10,11]. As in Jane Hirst's study, on 2702 pregnant women performed screening for GDM by testing 75 grams of sugar, with the Ameriacan Diabetes Association (ADA) 2010 standard, 6.1\% (164 women) being positive. However, when applying standards established by the IADPSG organization, up to $20.3 \%$ of pregnant women have to treat GDM $[8,12,13]$.

Managing of GDM is a multi-disciplinary combination, notably the role of obstetric, nutrition, endocrinology and neonatologists, with the goal of reducing adverse pregnancy outcomes and risks for mother through stabilizing and maintaining the target blood sugar level. Guidelines for GDM treatment of many Obstetrics 
associations agree a fundamental intervention for GDM is the change in lifestyle and medical nutria therapy (MNT) defined as the delivery of meals with the carbohydrate level controlled allows to provide adequate nutrition with reasonable weight gain, blood sugar control and avoid the risk of ketonimia. Many studies around the world have reported that the rate of blood sugar is stabilized immediately after abstimence from a few days to several weeks, ranging from $45-86 \%$ after $1-2$ weeks [14]. Some longer-term studies followed abstinence after 4 weeks, with success rates of more than $90 \%$ [5].

The risk of physical activity during pregnancy is very low, and is recommended for all pregnant women [7]. With a normal pregnancy, regular physical activity helps improve, maintain fitness, control weight gain, improve mental health. With GDM, physical activities is recommended as a component of lifestyle intervention therapy, which is an essential treatment in parallel with MNT $[7,11]$. All ADA, WHO, and IADSP agree that "the women with diabetes and diabetes do not have any internal medical condition or no obstetric complication should be encouraged to initiate or continue an average motor intensity as part of treatment " [11]. At the Fifth International Diabetes Federation, it was suggested, "A 30-minute daily exercise regime, encouraged movement such as brisk walking, arm exercises when sitting on a chair for at least 10 minutes after each meal helps achieve blood sugar goals" [4]. Recognizing the importance of combined abstinence in GDM management, we conducted the study: "The results of treatment of gestational diabetes with an abstinence diet combined with physical activity at Hung Vuong hospital in 2017-2018 ". The results are expected to be useful in evaluating the results of current diabetes treatment regimens as well as the desire to improve the effectiveness of hospital treatment and reproductive health in general. Research question: How is the effect of stabilizing blood sugar when combining dietary and physical exercise in treating GDM?

\section{Subjects and Methods}

Research design: Quasi Experimental Study

\section{Inclusive criteria}

All pregnant women with gestational diabetes treated with abstinence diet in High-risk pregnancy department, Hung Vuong hospital, HCMC from December 2017 to the end of April 2018. Single pregnancy, gestational age $\geq 28$ weeks. Literacy and understanding Vietnamese, agree to participate in research.

\section{Exclusion criteria}

Pregnancy GDM and insulin therapy. Abnormalities, pregnancy (placental placenta, placenta praevia, fetal distress, stillbirth). There are medical or obstetric conditions with contraindications to physical activity. Do not agree to participate in the study.

\section{Sample size}

The formula compares two averages of a target group be- fore and after the intervention: With $\mathrm{r}$ (correlation coefficient between 2 assessments). $C=7.85$ (when $\alpha=0.05$ and $\beta=0.2$ ). The study of dietary regime in combination with desirable exercise will reduce the average of $3 \mathrm{mg} / \mathrm{L}$ of pre-feeding blood glucose (finger blood sugar) according to the study of Anjana 2016 [6]. The maximum standard deviation for the largest sample size is 13. $E S=3 / 13=0.57$, the correlation coefficient is 0.7 . So according to the formula, calculate $\mathrm{N}=89$. Expected loss of $15 \%$ of samples should require at least 103 to ensure sample capacity. Actually obtaining 121 objects. Choose the whole sample until enough samples. The median physical activity is defined as "Low" when the total physical activity intensity is less than the median, "High" when the total physical activity intensity is higher than the median number.

\section{Adherence to abstinence}

Pregnant women eat properly according to the regime of the hospital on a daily menu, do not eat or drink anything other than the menu.

\section{Exercise adherence}

pregnant women perform 30 minutes of daily movement, for 5-7 days of treatment, each pregnant woman is given a time clock to ensure sufficient time for movement.

\section{Physical activity variables}

activity intensity levels calculated based on the questionnaire PPAQ (Pregnancy Physical Activity Questionnaire) standardized Vietnamese, including 32 physical activities divided into 4 groups: household/care activities (13 activities), career activities (5 activities), sports/exercise activities (8 activities) and travel activities ( 3 activities) and static/inactive activities (3 activities) ) $[3,13]$.

Each activity will be calculated based on the intensity and the total energy dissipated with the metabolic-hour equivalent unit (MET-hour). MET is the metabolic rate at rest, calculated as the amount of oxygen consumed at still sitting, equivalent to $3.5 \mathrm{ml}$ Oxygen $\mathrm{kg}$ weight/minute $(\approx 1,2 \mathrm{kcal} / 1$ minute for people weighing $70 \mathrm{~kg}$ Metabolic equivalents (MET-hours) are equal to the total energy dissipated by adding all activities, each activity will be divided into 4 groups according to intensity (sitting activity: <1.5 METs, Light activity: 1.5-<3.0METs, Average activity: 3.0 $-<6 \mathrm{METs}$, and Strong activity: $\geq 6.0 \mathrm{METs}$ ] [2]. Heavy consumption then calculated Full by multiplying the time spent on each activity each day with intensity. Use Stata 10 software to import and process data and analyze data. To assess the decrease in blood sugar levels at the time before and after the intervention, we use Signed rank test

\section{Result}

Table 1 Characteristics of the participants $(n=125) \&$ (Table 2-4) 


\section{Journal of Gynecology and Women's Health}

Table 1: Characteristics of the participants $(n=125)$.

\begin{tabular}{|c|c|c|}
\hline Characteristics & Frequency & Percentage (\%) \\
\hline \multicolumn{3}{|l|}{ People } \\
\hline Kinh & 121 & 96,08 \\
\hline Others & 4 & 3,20 \\
\hline \multicolumn{3}{|l|}{ Region } \\
\hline Urban & 84 & 67,20 \\
\hline Rural & 41 & 32,80 \\
\hline \multicolumn{3}{|l|}{ Mother age } \\
\hline \multicolumn{3}{|l|}{ Mean: $29,4 \pm 4,86$ years old } \\
\hline$<25$ & 20 & 16,00 \\
\hline $25-34$ & 83 & 66,40 \\
\hline$\geq 35$ & 22 & 17,60 \\
\hline \multicolumn{3}{|l|}{ Career } \\
\hline Workers, salers & 45 & 36,00 \\
\hline Jobholders & 39 & 31,20 \\
\hline housekeepers & 25 & 20,00 \\
\hline Others & 16 & 12,80 \\
\hline \multicolumn{3}{|l|}{ Literacy } \\
\hline Unfinished high school & 15 & 12,00 \\
\hline Graduated and post graduated high school & 110 & 88,00 \\
\hline \multicolumn{3}{|l|}{ Recent Children } \\
\hline Not at all & 64 & 51,20 \\
\hline$\geq 1$ child & 61 & 48,8 \\
\hline \multicolumn{3}{|l|}{ Family Income/ Month(Vndong) } \\
\hline Less than 10 million & 25 & 20,00 \\
\hline $10-<20$ million & 67 & 53,60 \\
\hline From 20 million & 33 & 26,40 \\
\hline
\end{tabular}

Table 2: The stability of blood sugar level after intervention.

\begin{tabular}{|c|c|c|}
\hline Blood Sugar Level & Stability, N\% & Unstability, N\% \\
\hline After 3 days & $89(71,20)$ & $36(28,80)$ \\
\hline After 5 days & $106(84,80)$ & $19(15,20)$ \\
\hline After 7 days & $109(87,20)$ & $16(12,08)$ \\
\hline
\end{tabular}

Table 3: Logistics Regression analysis variables related intervention.

\begin{tabular}{|c|c|c|c|c|c|}
\hline \multirow{2}{*}{ Variables } & \multicolumn{2}{|c|}{ Blood Sugar Level After 7 Days of Intervention } & \multirow{2}{*}{$\mathbf{R R}$} & \multirow{2}{*}{ KTC $95 \%$} & \multirow{2}{*}{$\mathbf{P}^{*}$} \\
\hline & Stable & Unstable & & & \\
\hline \multicolumn{6}{|c|}{ Follow Up Strictly Nutritional Diet } \\
\hline Yes & $6(27,27)$ & $16(72,73)$ & Ref & $1,03-6,92$ & 0,04 \\
\hline No & $103(100,00)$ & $0(00,00)$ & 2,67 & & \\
\hline \multicolumn{6}{|c|}{ Physical Activities } \\
\hline Yes & $5(33,33)$ & $10(66,67)$ & Ref & $0,57-4,17$ & 0,39 \\
\hline No & $104(94,55)$ & $6(5,45)$ & 1,54 & & \\
\hline \multicolumn{6}{|c|}{ BMI Before Pregnancy } \\
\hline$<23$ & $91(96,81)$ & $3(3,19)$ & Ref & $0,46-1,46$ & 0,51 \\
\hline$\geq 23$ & $18(58,06)$ & $13(41,94)$ & 0,82 & & \\
\hline
\end{tabular}




\section{Journal of Gynecology and Women's Health}

\begin{tabular}{|c|c|c|c|c|c|}
\hline \multicolumn{5}{|c|}{ Previous GDM } & $0,41-1,81$ \\
\hline No & $100(91,74)$ & $12(11,65)$ & Ref & 0,70 \\
\hline Yes & $9(56,25)$ & $7(43,75)$ & 0,86 & & \\
\hline
\end{tabular}

(*) Multiple variable logistics regression

Table 4: Distribution of physical activity intension (Met-hour/week).

\begin{tabular}{|c|c|}
\hline Physical Activities & Median $\left(25^{\text {th }}-75^{\text {th }}\right)$ \\
\hline Total intension of physical activities (Met-hour/week) & $112,27(98,725-123,2)$ \\
\hline \multicolumn{2}{|c|}{ Physical Activities by Intensive Levels } \\
\hline Sitting & $37,275(21,35-46,475)$ \\
\hline Low intensive level & $30,1(21,6-43,225)$ \\
\hline Average intensive level & $30,9(23,675-46,05)$ \\
\hline High intensive level & 0 \\
\hline \multicolumn{2}{|c|}{ Physical Activities by Work Content } \\
\hline House keeping & $37,275(26,25-51,1)$ \\
\hline Office Jobs & $42,7(23,975-61,25)$ \\
\hline Doing exercise & $1,625(0,8-2,675)$ \\
\hline Walking & $25,2(17,675-32,55)$ \\
\hline
\end{tabular}

\section{Discussion}

The study with 125 pregnant women participated in the intervention and monitored blood sugar (fingertips) 4 times/ day. Pregnant women with target blood glucose $\geq 70 \%$ of the total value of monitored blood sugar are considered to have stable blood glucose levels. According to the treatment regimen, women are considered successful treatment and discharged after 5 days. Results, after 3 days of treatment, 89 pregnant women were able to stabilize blood sugar, accounting for $71.2 \%$ and after 5 days,
106 pregnant women achieved blood sugar targets, accounting for $84.8 \%$. Only 19 pregnant women, accounting for $15.2 \%$, need to review, adjust the diet and exercise, continue to monitor for 2 days. In the next 2 days, in 19 pregnant women, 3 more cases (15.7\%) achieved stable blood sugar, 16 women (84.3\%) did not reach the target blood sugar, had to consider using more insulin, is considered a failure to treat. Thus, the ratio of stable pregnant women to blood sugar after 3 days is $71.2 \% 95 \%$ CI [63.2-79.1], 5 days is $84.8 \% 95 \%$ CI [78.5-91.0 ] and 7 days were $87.2 \% 95 \%$ CI [81.3-90.0], $\mathrm{P}<0.05$.

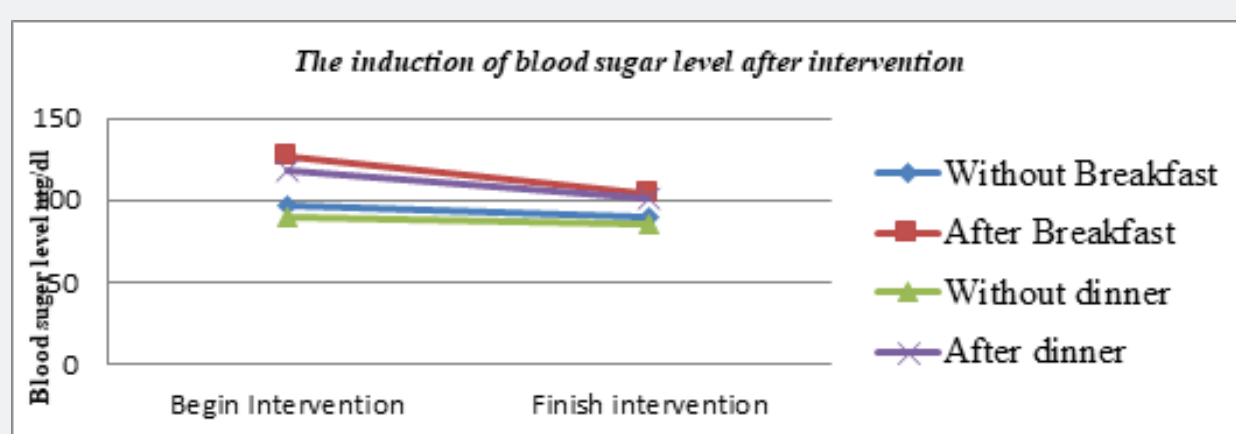

Figure 1: The induction of blood sugar level after intervention.

According to the results from Table 2 and Figure 1, all glycemic indexes were statistically significant ( $p<0.001)$ after intervention. The results of this study are similar to the research of Ram Uma and Anjana, who performed GDM treatment according to WING-MOC care intervention (the project to treat pregnant women with diabetes in India based on the recommendation of International Diabetes Federation) [1]. Specifically, in Anjana's study, 151 GDM pregnant women were treated for MNT and physical activity by walking with a step counter with a walking diary and a step number meter was included [1]. After the end of the intervention, there was a reduction in fasting blood sugar, blood sugar after meal 1 hour and 2 hours $(\mathrm{p}<0.001)$. The authors report a moderate reduction in fasting blood glucose of $3.0 \mathrm{mg} / \mathrm{dl}$ (with fasting blood glucose before MOC: $89 \mathrm{mg} / \mathrm{dl}$, after MOC: $85 \mathrm{mg} / \mathrm{dl}, \mathrm{p}<0.001$ ), lower than our study. However, at the 2-hour postprandial blood glucose level, blood sugar reduction was higher than $-35 \mathrm{mg}$ / dl (blood sugar 2 hours before MOC: 148mg / dl, after MOC 
$111 \mathrm{mg} / \mathrm{dl}, \mathrm{p}<0.001)$. The difference may be due to the longer duration of treatment ( 2 weeks after intervention) compared to us ( 1 week), making the 2-hour postprandial blood glucose level more stable. This is in line with trials that demonstrate the long-term effects of physical activity on the improvement of hepatic glucose tolerance (through postprandial hypoglycemia), maintaining stable blood sugar levels (through stability HbA1c) [14]. Also with the 2017 WING-MOC intervention, Uma reported the rate of stabilizing blood sugar with MNT and walking on 212 pregnant women after 84 weeks of intervention. This result is lower than our study (blood glucose stabilization rate $87.2 \%$, but only after 5-7 days). Perhaps because in our study, all pregnant women received inpatient treatment, with the calculated diet and physical activity monitored and monitored closely leading to higher compliance rates, with can help quickly achieve stable blood sugar levels.

In order to compare, and to find a valuable and reliable tool to evaluate physical activity for pregnant women. Author Matteo Sattler in 2018 conducted a meta-analysis of 18 studies with 11 questionnaires evaluating different physical activity during pregnancy. The author noted that PPAQ questionnaire showed advantages over other questionnaires in both value and reliability [13]. Also in this study, the Vietnamese version of PPAQ was also reported with an ICC correlation coefficient of 0.87-0.94 for all areas including activity intensity levels and activity types. Although PPAQ has not achieved reliability and cumulative value (perhaps due to lack of standards in how to obtain data), the author also recommends using PPAQ instead of the remaining questionnaires [13]. Therefore, in this study, we use Vietnamese transliterated PPAQ questions to assess the physical activity of the subjects in the study. Thus, from the results of table 3.3, pregnant women have a total physical activity intensity of 112.27 Met-hours / week. Another study with a similar design by Nguyen Cong Luat 2018, performed on 2030 Vietnamese pregnant women from 6 major hospitals across the country, including Hung Vuong hospital, recorded the total activity intensity. force is 116.6 Met-hours/week [12]. These study also compared the intensity of physical activity between two groups with and without GDM, both recorded GDM subgroups had a lower total activity intensity than normal pregnant women $(p<0,05)$ [12].

\section{Limitation of the Study}

In this study, we only evaluated the effectiveness of the intervention through the short-term outcome of the rate of stable blood glucose as well as the reduction of fasting blood sugar and postprandial blood glucose 2 hours after the intervention. Longterm outcomes such as: rate of macrosimia, stillbirth, preterm, birthing, caesarean section were not investigated. The biggest drawback of our study is that there is no control group, we cannot compare the outcome between the group with and without intervention. Assessing the level of movement through a set of questions makes it easy to make mistakes due to recall.

\section{Conclusion}

Results of treatment of diabetic patients with dietary regime combining physical fitness in Hung Vuong hospital in 125 cases, we draw some conclusions as follows:

a) The rate of pregnant women with diabetes with stable blood sugar after 3.5.7 days of treating nutritional abstinence with physical activity by walking 30 minutes a day is $71.2 \%$ 95\% CI [63.2-79.1], 84.8\% 95\% CI [78.5-91.0], 87.2\% 95\% CI [81.3-90.0], $\mathrm{P}<0.05$.

b) Nutritional adherence of combined motion modulation increases the rate of glycemic stabilization with $\mathrm{RR}=2.67$ 95\% CI [1.03-6.92], P <0.05. Other factors that have not been recorded are statistically significant differences.

c) Total physical activity intensity of participants: 112.27 Met-hours/week.

\section{References}

1. Anjana RM, Sudha V, Lakshmipriya N, Anitha C, Unnikrishnan R, et al (2016) Physical activity patterns and gestational diabetes outcomesThe wings project. Diabetes Res Clin Pract 116: 253-262.

2. Berntsen S, Richardsen KR, Morkrid K, Sletner L, Birkeland KI, et al. (2014) Objectively recorded physical activity in early pregnancy: a multiethnic population-based study. Scand J Med Sci Sports 24(3): 594-601.

3. Chasan-Taber L, Schmidt MD, Roberts DE, Hosmer D, Markenson G, et al. (2004) Development and validation of a Pregnancy Physical Activity Questionnaire. Med Sci Sports Exerc 36(10): 1750-1760.

4. Cho NH, Shaw JE, Karuranga S, Huang Y, da Rocha Fernandes JD, et al. (2018) IDF Diabetes Atlas: Global estimates of diabetes prevalence for 2017 and projections for 2045. Diabetes Res Clin Pract 138: 271-281.

5. Giuffrida FM, Castro AA, Atallah AN, Dib SA (2003) Diet plus insulin compared to diet alone in the treatment of gestational diabetes mellitus: a systematic review. Braz J Med Biol Res 36(10): 1297-300.

6. Harrison AL, Shields N, Taylor NF, Frawley HC (2016) Exercise improves glycaemic control in women diagnosed with gestational diabetes mellitus: a systematic review. J Physiother 62(4): 188-196.

7. Haskell WL, Lee IM, Pate RR, Powell KE, Blair SN, et al. (2007) Physical activity and public health: updated recommendation for adults from the American College of Sports Medicine and the American Heart Association. Med Sci Sports Exerc 39(8): 1423-1434.

8. Hirst JE, Tran TS, Do MA, Morris JM, Jeffery HE, et al. (2012) Consequences of gestational diabetes in an urban hospital in Viet Nam: a prospective cohort study. PLoS Med 9(7): e1001272.

9. Hirst JE, Tran TS, Do MA, Rowena F, Morris JM, et al. (2012) Women with gestational diabetes in Vietnam: a qualitative study to determine attitudes and health behaviours. BMC Pregnancy Childbirth 12: 81.

10. LHeveder R, Nolan $T$ (2013) International Diabetes Federation. Diabetes Res Clin Pract 101(3): 349-351.

11. Michelle M, Stephanie-May R (2011) Exercise Guidelines for Women with Gestational Diabetes. Canada, pp. 340-346.

12. Nguyen CL, Pham NM, Lee AH, Nguyen PTH, Chu TK, et al. (2018) Physical activity during pregnancy is associated with a lower prevalence of gestational diabetes mellitus in Vietnam. Acta Diabetol 55(9): 955-962. 
13. Sattler MC, Jaunig J, Watson ED, Poppel VMN, Mokkink LB, et al. (2018) Physical Activity Questionnaires for Pregnancy: A Systematic Review of Measurement Properties. Sports Med 48(10): 2317-2346.

14. Yamamoto, Kellett JE, Garcia-Patterson A, Balsells M (2018) Gestational Diabetes Mellitus and Diet: A Systematic Review and Meta-analysis

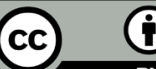

his work is licensed under Creative Commons Attribution 4.0 License BY DOI: 10.19080/JGWH.2019.15.555905 of Randomized Controlled Trials Examining the Impact of Modified Dietary Interventions on Maternal Glucose Control and Neonatal Birth Weight. Diabetes Care 41(7): 1346-1361.

\section{Your next submission with Juniper Publishers will reach you the below assets}

- Quality Editorial service

- Swift Peer Review

- Reprints availability

- E-prints Service

- Manuscript Podcast for convenient understanding

- Global attainment for your research

- Manuscript accessibility in different formats

( Pdf, E-pub, Full Text, Audio)

- Unceasing customer service

Track the below URL for one-step submission https://juniperpublishers.com/online-submission.php 